\title{
OPEN
}

\section{The TA Manifesto}

\begin{abstract}
A common statement from the organizations involved in the PACITA project, the PACITA manifesto argues for the necessity of European political support of future efforts to expand technology assessment (TA) capacities in the European member states. The authors posit the tradition of technology assessment in European as a democratic project to inform policy makers on societal and environmental topics related to science, technology and innovation. And they call attention to the necessity of countering the increasing influence of science and technology on societal development and policy making with increasing capacities for technology assessment. Developing a more comprehensive 'policyoriented' approach to TA is called for by the authors along with an increase in cross-European collaboration in TA.

Klüver, Lars, Rasmus Øjvind Nielsen, and Marie Louise Jørgensen, eds. Policy-Oriented Technology Assessment Across Europe: Expanding Capacities. Basingstoke: Palgrave Macmillan, 2016. DOI: 10.1057/9781137561725.0008.
\end{abstract}




\section{Expanding knowledge-based policy making on science, technology and innovation}

Technology is a central element in the policy response to the great challenges of our time, such as ageing societies, climate change and public health. In addition, emerging technologies such as synthetic biology, nanotechnology and the ever-changing Internet all challenge established policies. The encompassing quality of technology today is influencing the lives of citizens all over the world. The global transforming power of technology, thus, has to be aligned with policy making and democracy.

Technology assessment (TA) can be seen as a democratic project in Europe, providing and supporting robust and knowledge-based policy making on societal topics related to science, technology and innovation. It has mostly been established in the western parts of Europe and in connection to national parliaments.

Technology development and policies are becoming transnational. At the same time, the need for multilevel action on the grand challenges of our societies is obvious. Modern policy making needs to bridge these transnational and multilevel dimensions of the development, regulation, implementation and management of technology. The rapid technological development, in combination with science and technology's profound influence on societal developments and policy making, call for an important and increasing role for European TA in the future.

The PACITA project has during 2011-15 enhanced European TA by:

- enhancing the capacity for doing TA in and across European nations;

- increasing cross-European collaboration in TA;

- expanding the institutionalization of TA across Europe;

- developing the conceptual framework of TA into a more comprehensive 'policy-oriented approach', adding to the traditional parliamentary-oriented TA in Europe;

- raising awareness about the possibilities for modern policymaking that lies in TA.

\section{TA - a multi-level and cross-border European capacity for the future}

The PACITA project should be seen as a new setoff for a necessary expansion of the European TA landscape: 
TA should collaborate to increase the capacity of providing robust and independent policy advice for policy makers in all of Europe. As the EU grows and Europe becomes more connected, TA can through strong knowledge sharing and collaboration contribute to knowledge exchange and synergies, which provide for widespread use of the independent and knowledge-based advice from TA. Countries should help each other by sharing TA knowledge and outcomes.

TA should be institutionalized in all European countries in order to provide for independent knowledge-based advice and to promote the engagement of stakeholders, experts, citizens and policy makers in a collaborative, democratic provision of policy options. The diversity in cultures and political contexts in Europe call for national implementation of TA in ways which are optimal for the single nation. For Europe to develop strong knowledge-based and democratic decision making, TA needs to be implemented in all European states.

There is a clear political call for increased parliamentary dialogue across Europe on the technological development and its meaning for our societies. TA should play an active role in setting up that dialogue. In a context of globalization and European construction, policy making on many science- and technology-related issues needs a cross-border approach. As stated by two parliamentary meetings in PACITA, TA has an important role to play in setting up parliamentary dialogue across Europe.

Citizens in Europe have a democratic right to be heard about the technological development since technology is strongly influencing their lives. PACITA has proven that TA has the methodology to make that right happen on the European level. Over the years, TA has developed a toolbox of methods and approaches for engaging different groups of actors, and especially the involvement of citizens in policy debates. Seeing that the 'grand challenges' will demand an understanding of scientific and technological analysis as well as of societal values, TA is well suited to giving advice on these topics, also based upon citizen engagement.

Strong TA collaboration on the project level across Europe should be encouraged and supported. The development of technology moves forward with increasing pace. Because these developments happen on a European and international level, the need for cross-European TA is evident. Collaboration between countries and institutions will ensure that knowledge from experienced TA units is combined with new thoughts and ideas from emerging TA actors. 
TA has a crucial role to play in the European strive for ensuring societally responsible research and innovation. Responsible Research and Innovation (RRI) has shaped the recent years' policy discourse in Europe related to the societal role of research and innovation. It has given greater focus to key concepts in TA, such as participation, forward-thinking, reflexivity and policy action. TA can and should be a key carrier of the concept and should play a light-house role in RRI.

(c) (i) Except where otherwise noted, this work is licensed under a copy of this license, visit https://creativecommons.org/version4 